\title{
Modeling Tidal Current Profiles and Vertical Mixing beneath Filchner-Ronne Ice Shelf, Antarctica
}

\author{
KEITH MAKINSON \\ British Antarctic Survey, Natural Environment Research Council, Cambridge, United Kingdom
}

(Manuscript received 8 January 2001, in final form 6 July 2001)

\begin{abstract}
One of the warmest water masses beneath Filchner-Ronne Ice Shelf (FRIS) is dense, high salinity shelf water (HSSW) that flows into the sub-ice-shelf cavity from the ice front and occupies the lower portion of the water column. A one-dimensional turbulence closure ocean model has been applied to this high latitude sub-ice-shelf environment to demonstrate that tidal currents mix HSSW vertically through the water column and cause melting at the bottom of the ice shelf. Significantly FRIS lies near the critical latitude for the semidiurnal tide, where the Coriolis frequency equals the tidal frequency, resulting in a strongly depth-dependent tidal current and thick boundary layers. Using the model, the effect of the critical latitude, stratification, and the polarization of the tidal current ellipse on boundary layer structure and subsequent vertical mixing are examined. The model shows that stratification significantly affects how the shape of the tidal current ellipse varies with depth and that both the depth to which the pycnocline initially develops and the longer term melt rates are highly dependent on tidal current ellipse polarization. The sensitivity to both the stratification and the polarization are due, in large part, to the proximity of the critical latitude. Positive polarizations (anticlockwise rotating current vectors) quickly develop deeper pycnoclines and maintain higher melt rates than negative polarizations (clockwise rotating current vectors). For many areas beneath FRIS the polarization ranges from -0.3 to +0.3 ; here the modeled pycnocline development is sensitive to polarization, though the effect on the time-averaged melt rate is suppressed for positive polarizations. However, in key areas where the polarization exceeds \pm 0.3 and the ellipses are more open and circular, the effects of polarization are significant. Levels of tidal mixing and associated melting vary by more than an order of magnitude over the whole tidal ellipse polarization range, showing that very different mixing and melting regimes are present beneath FRIS.
\end{abstract}

\section{Introduction}

The largest mass of floating ice on earth is located in the southern Weddell Sea at the margin of the Antarctic ice sheet. The Filchner-Ronne system of ice shelves (FRIS) (Fig. 1) is a floating extension of the Antarctic Ice Sheet, draining $24 \%$ of the area of the continent's grounded ice and covering an area slightly less than that of France (Fox and Cooper 1994). Direct oceanographic measurements from beneath FRIS confirm that high salinity shelf water (HSSW), a product of sea ice formation north of the ice shelf, flows into the sub-ice-shelf cavity (Nicholls and Makinson 1998; Nicholls et al. 2001). This relatively warm, dense water occupies the lower portion of the water column in an environment isolated from atmospheric forcing, in which tidal and thermohaline processes are thought to dominate the circulation. MacAyeal (1984) suggested tidal stirring as a probable mechanism for mixing HSSW up through the sub-ice-shelf water column to be

Corresponding author address: Keith Makinson, British Antarctic Survey, Natural Environment Research Council, High Cross, Madingley Road, Cambridge CB3 0ET, United Kingdom.

E-mail: kmak@bas.ac.uk transformed, through melting at the underside of the ice shelf, into ice shelf water (ISW). Since ISW is a precursor of Antarctic Bottom Water (Foldvik and Gammelsrød 1988) and Southern Ocean bottom water formation takes place mostly in the Weddell Sea (Ganachaud and Wunsch 2000), mixing processes beneath FRIS are potentially significant for global ocean circulation.

In the cavity beneath an ice shelf frictional stress at both the seabed and the ice shelf base influences the vertical structure of tidal currents, induces vertical mixing, and enables the development of two well-defined mixed boundary layers. These frictional boundary layers are made up of a thin region of high shear and a thicker region of low shear. Beyond this boundary layer is the free stream region where there is no shear and where the current is independent of depth (Soulsby 1983). Where fixed ice cover is present and tidal currents in deep water are weak, the frictional boundary layers occupy a small fraction of the water column. However, in shallow water with strong tidal currents, they can occupy the entire water column, dominating the tidal current structure and associated vertical mixing (Prinsenberg and Bennett 1989). Tidal simulations for 


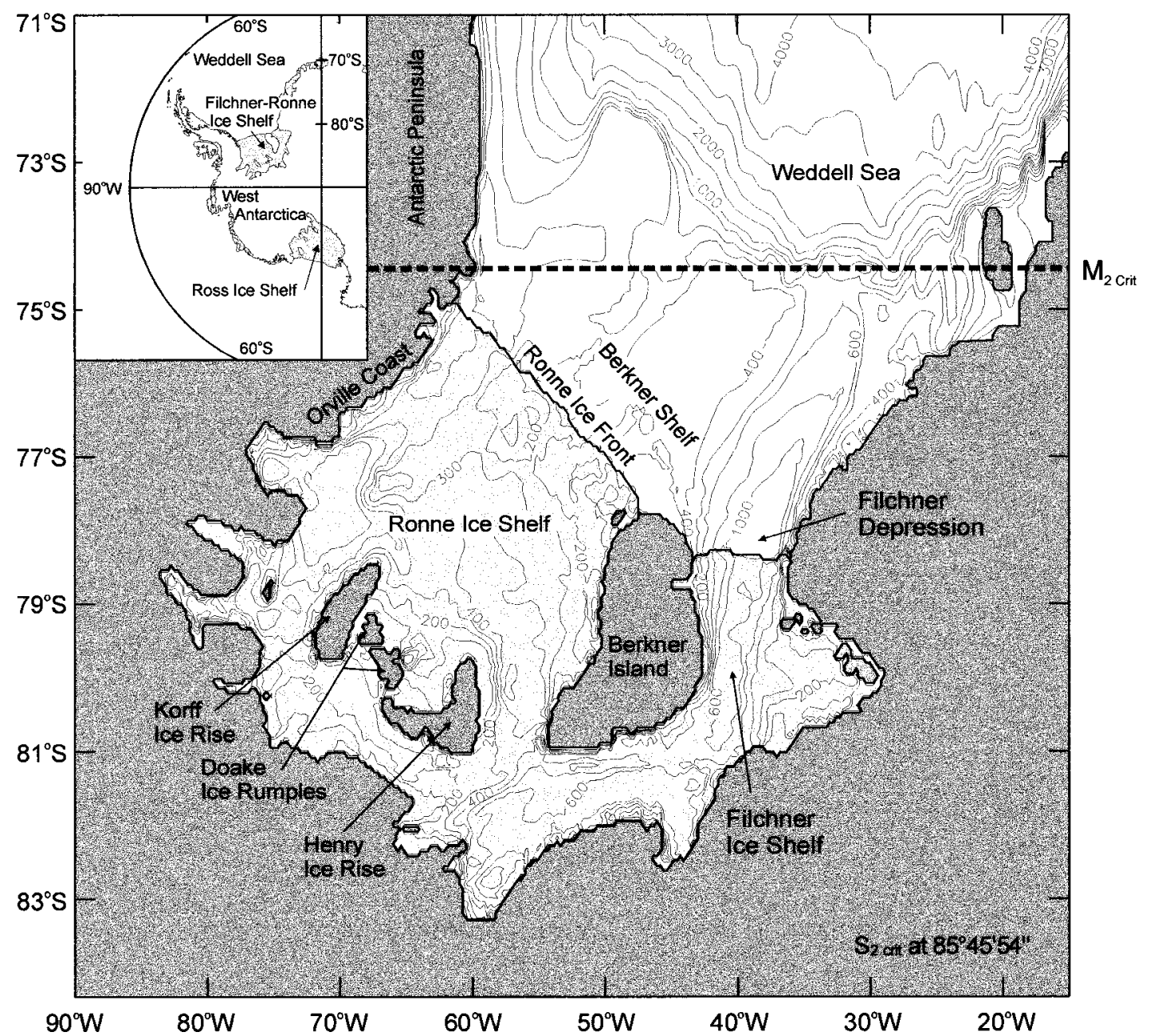

FIG. 1. Map showing the water column thickness in the area of Filchner-Ronne Ice Shelf and extending over the continental shelf. The contours give water column thickness in meters. The darkest shading indicates areas of grounded ice, and the lighter shading indicates the floating ice shelf. The critical latitude for the semidiurnal tidal constituent $M_{2}$ is indicated by the dashed line and the inset indicates the position of FRIS in the southern Weddell Sea.

the southern Weddell Sea show that the mean barotropic tidal currents beneath FRIS attain speeds of up to $0.2-$ $0.5 \mathrm{~m} \mathrm{~s}^{-1}$, with peak velocities reaching $1 \mathrm{~m} \mathrm{~s}^{-1}$ (Makinson and Nicholls 1999; Robertson et al. 1998). Close to the Ronne Ice Front, and along grounding lines of FRIS where the ice first comes afloat, these tidal currents are thought to result in significant levels of vertical mixing, and high basal melt rates.

To determine the influence of vertical tidal mixing on melting beneath Ross Ice Shelf, Scheduikat and Olbers (1990) developed two one-dimensional mixed layer models, thermodynamically coupled to an ice shelf, one with two layers and one with three layers. Both were Kraus and Turner type models (Kraus and Turner 1967), which were forced by a barotropic tidal current. In the two-layer model, the horizontally homogeneous upper mixed layer interacted with the ice shelf while the lower layer remained passive and represented an infinite heat and salt reservoir. In the three-layer model, the bottom layer was treated as a mixed layer and included the advection of heat and salt, while a third layer was introduced between the two mixed layers. With the twolayer model it was found that basal melting or freezing was strongly dependent on the ratio of the major and minor axes of the tidal current ellipse. Flat or degenerate ellipses yielded cyclic currents with the top layer entraining and then detraining water from the layer below. When the current was at its maximum during the tidal cycle, entrainment and melting would occur. With open, circular ellipses there was little or no entrainment from the layer below and heat lost from the upper layer to the ice shelf gave a small amount of freezing, irrespective of the tidal current amplitude. The three-layer model gave similar results, but with reduced melt rates resulting from a better representation of the thermocline. Scheduikat and Olbers (1990), however, did not include the effects of the earth's rotation.

Using a one-dimensional turbulence closure model 
that included the earth's rotation, Simpson and Sharples (1994) considered the effects of tidal current ellipse polarization on tidal front behavior. Polarization $(P)$ is used to define the shape and sense of rotation of a tidal current ellipse

$$
P= \pm V / U
$$

where $U$ and $V$ are the semimajor and semiminor axes of the tidal current ellipse, respectively. The polarization ranges from a purely circular clockwise current $(P=$ $-1)$, through a flat or degenerate ellipse $(P=0)$, to a purely circular anticlockwise current $(P=+1)$. With the inclusion of rotation, Simpson and Sharples (1994) found that predominantly clockwise tidal currents (in the Northern Hemisphere) produced substantial differences in the predicted positions of fronts over previous nonrotational models, with fronts extending into deeper waters where the polarization was increasingly negative.

The rotational effect on vertical mixing is accounted for by decomposing the elliptical tidal current into purely anticlockwise $\left(R_{+}\right)$and clockwise $\left(R_{-}\right)$components and considering their respective frictional boundary layers. The two constant magnitude rotary velocity components rotate at the tidal frequency, and each has a characteristic frictional boundary layer thickness, $\delta_{+}$ and $\delta_{-}$, given by (Prandle 1982):

$$
\begin{aligned}
& \delta_{+} \approx\left(\frac{2 K_{M}}{|\omega+f|}\right)^{1 / 2} \text { and } \\
& \delta_{-} \approx\left(\frac{2 K_{M}}{|\omega-f|}\right)^{1 / 2},
\end{aligned}
$$

where $K_{M}$ is the eddy viscosity, $f$ is the Coriolis parameter, and $\omega$ the frequency of the tidal oscillation. Assuming a constant eddy viscosity for semidiurnal tides at northern midlatitudes the thickness of the clockwise frictional boundary layer will be about three times greater than for the anticlockwise frictional boundary layer. An effective combined boundary layer thickness $(\delta)$ is suggested by Soulsby (1983)

$$
\delta=\frac{\left(R_{+} \delta_{+}+R_{-} \delta_{-}\right)}{\left(R_{+}+R_{-}\right)} .
$$

Consequently, tidal currents with more negative polarizations in the Northern Hemisphere have larger boundary layers, allowing mixing to penetrate farther into the water column interior and tidal fronts to advance into deeper water.

The spatial variability of the tidal currents beneath FRIS was determined by Makinson and Nicholls (1999) using a two-dimensional depth-averaged barotropic tidal model of the southern Weddell Sea. The $M_{2}$ tidal ellipse polarization over this region is shown in Fig. 2. All the semidiurnal tidal constituents exhibit an almost identical pattern of polarization with regions of strongly positive and negative polarization present beneath FRIS, suggesting a wide range of boundary layer depths.
At higher northern latitudes the boundary layer of $R_{-}$ is much larger than the $R_{+}$component as $|\omega-f|$ tends to zero at the critical latitude $\left(\varphi_{\text {crit }}\right)$. At this latitude the tidal frequency equals the Coriolis or inertial frequency, $\omega=|f|=2 \Omega \sin \varphi_{\text {crit }}$, where the earth's angular velocity $\Omega=7.2921151 \times 10^{-5} \mathrm{rad} \mathrm{s}^{-1}$. Furevik and Foldvik (1996) showed that a thick benthic boundary layer develops as the critical latitude is approached. A thicker boundary layer produces less intense shear near boundaries but extends the shear over a larger thickness of the water column, and is likely to enhance vertical mixing near the critical latitude.

In the Southern Hemisphere, the northwest corner of FRIS lies near the critical latitude of the $M_{2}$ tidal constituent at $74^{\circ} 28^{\prime} 18^{\prime \prime} \mathrm{S}$, while the southernmost areas of the ice shelf are closest to the $S_{2}$ critical latitude at $85^{\circ} 45^{\prime} 54^{\prime \prime} \mathrm{S}$. In the shallow regions close to the Ronne Ice Front, south of Henry Ice Rise and along grounding lines, the combined effects of strong tidal currents and the proximity of the critical latitude will further thicken the boundary layers. This produces extensive areas over which the boundary layers may occupy the entire water column, and here the free stream region of the tidal current will be absent. At high latitudes the diurnal tides do not exhibit these large differences between the thickness of the boundary layers of $R_{+}$and $R_{-}$as, for these frequencies; $|f|$ is almost twice as large as $\omega$.

Boundary layer thickness is further complicated by the stratifying effect of any buoyancy input. The only source of buoyancy beneath FRIS is the net production of an estimated $1500-3000 \mathrm{~m}^{3} \mathrm{~s}^{-1}$ of meltwater (Nicholls and Makinson 1998), which is critical for driving the circulation over large areas of the region and has important implications for water column structure. Buoyancy effects caused by freezing or melting under sea ice have been found to play an important role in modifying turbulent processes (Shirasawa and Ingram 1991). During melting the water column becomes stratified while the tidal forcing remains unchanged. The effect of stratification is to suppress turbulence, inhibiting the transfer of momentum and reducing the eddy viscosity, hence reducing the boundary layer thickness from the homogenous case (Souza and Simpson 1996). Further modification of the vertical tidal current structure occurs in the vicinity of the pycnocline, which becomes decoupled from the mixed layers at the seabed and ice base (Prinsenberg and Bennett 1989). Near the critical latitude, the influence of eddy viscosity on the vertical tidal current profiles is significant (Nøst 1994): a small change results in a large variation in the anticlockwise component in the Southern Hemisphere, while the clockwise component remains unaffected.

Effects of tides are usually ignored within sub-iceshelf circulation models. For FRIS, this means that the estimated $25 \mathrm{GW}$ of tidal energy dissipation associated with surface friction are also ignored (Makinson and Nicholls 1999; Robertson et al. 1998). Vertical mixing resulting from tidal currents has been parameterized 


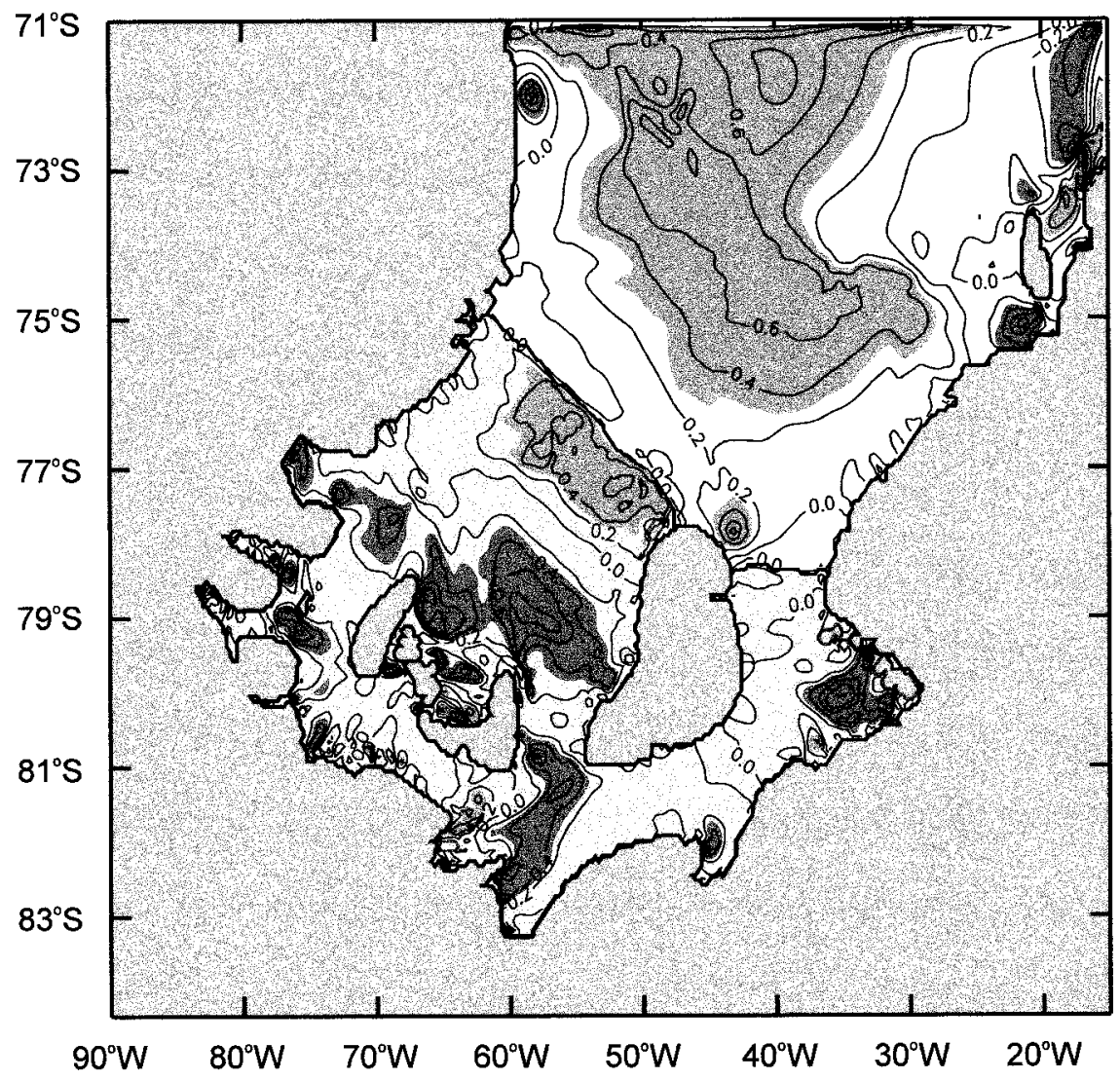

FIG. 2. The $M_{2}$ tidal current ellipse polarization of the depth-averaged velocity predicted by Makinson and Nicholls (1999) for the southern Weddell Sea. The contours have a 0.2 spacing. The darkest shading shows regions of strong clockwise rotation $(P<-0.3)$, the lighter shading shows regions of strong anticlockwise rotation $(P>0.3)$.

only as a function of average water column speeds derived from two-dimensional barotropic tidal models (Makinson and Nicholls 1999; MacAyeal 1984). This parameterization is poor for high-latitude regions dominated by semidiurnal tides with a wide range of tidal current ellipse polarizations.

In this paper a one-dimensional ocean model, coupled thermodynamically to the ice shelf, is applied to a subice-shelf water column to study vertical profiles of tidal currents, vertical mixing, and basal melting beneath Filchner-Ronne Ice Shelf. The model is described in the next section, together with the parameters used to define the model properties and the initial conditions. Results from the model in section 3 show the proximity to the $M_{2}$ and $S_{2}$ critical latitudes affects the vertical tidal current structure and how this is further affected by the presence of stratification. Also described are the effects of depth-averaged tidal current ellipse polarization on vertical mixing and basal melting over a wide range of polarizations and current amplitudes. The implications for FRIS of the results from the mixing model are then discussed.

\section{Model description}

The one-dimensional model uses an implicit finite difference scheme to integrate the horizontal velocity components $(u, v)$ of the momentum equations

$$
\begin{aligned}
& \frac{\partial u}{\partial t}=-S_{x} g \sin \left(\omega t-\phi_{x}\right)+f v+\frac{\partial}{\partial z}\left(K_{M} \frac{\partial u}{\partial z}\right) \text { and } \\
& \frac{\partial v}{\partial t}=-S_{y} g \sin \left(\omega t-\phi_{y}\right)-f u+\frac{\partial}{\partial z}\left(K_{M} \frac{\partial v}{\partial z}\right)
\end{aligned}
$$

with $x$ and $y$ positive in the east and north directions and $z$ increasing positively upward, with $z=0$ at the ice-ocean boundary and $z=-h$ at the seabed. Here, $K_{M}$ is the vertical eddy viscosity, $f$ is the Coriolis parameter, $g$ the gravitational acceleration, and $\omega$ is the tidal frequency; $S_{x}, S_{y}$ and $\phi_{x}, \phi_{y}$ are the prescribed tidal surface slope amplitudes and phases. A phase difference of $\pi / 2$ is maintained between $\phi_{x}$ and $\phi_{y}$, while the amplitude of the tidal slopes are determined from 


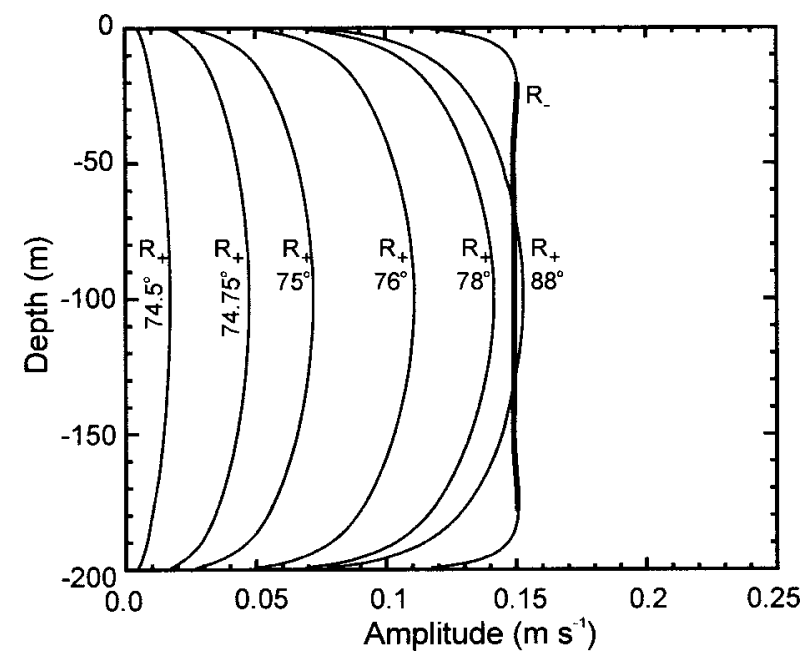

FIG. 3. The vertical structure of the $M_{2}$ rotary components in a 200-m homogeneous water column beneath an ice shelf. The clockwise component $\left(R_{-}\right)$has small boundary layers, while the boundary layers of the anticlockwise component $\left(R_{+}\right)$occupy the whole water column. As the $M_{2}$ critical latitude at $74^{\circ} 28^{\prime} 18^{\prime \prime} \mathrm{S}$ is approached from the south the anticlockwise component $\left(R_{+}\right)$of the flow is retarded while $\left(R_{-}\right)$remains unchanged. The free stream region of $R_{-}$is highlighted in bold.

$$
\begin{aligned}
& S_{x}=\frac{U(\omega+P f)}{g} \\
& S_{y}=\frac{U(f+P \omega)}{g},
\end{aligned}
$$

where $U$ determines the maximum speed of the tidal current (semimajor axis) and $P$, which ranges between \pm 1.0 , controls the polarization of the tidal current ellipse. More details on the derivation of (7) and (8) are given in the appendix. At both the ice-ocean interface and the seabed, a quadratic drag law is applied with a drag coefficient of $C_{d 100}=0.0025$. A smoothly graded vertical mesh is used to give the highest resolution at the boundaries. The thickness of the two layers adjacent to each of the boundaries are set to $1.0 \mathrm{~m}$. The node depth at the center of each layer of the remaining water column $\left(z_{\text {rem }}\right)$ is determined from Lynch et al. (1996)

$$
Z_{\text {node }}=-z_{\text {rem }}+\varepsilon\left(z_{\text {rem }}\right)-\beta \sin (2 \pi \varepsilon),
$$

where $\varepsilon$ increases linearly with node number from 0 at the bottom to 1 at the top. For a total water column thickness of $200 \mathrm{~m}$ with 61 nodes, the constant $\beta$ is set to give the desired layer resolution of $1.0 \mathrm{~m}$ near the boundaries and approximately $6 \mathrm{~m}$ in the mid-water column.

Both heat and salt are conserved in the model and their vertical diffusion within the water column are governed in the model by

$$
\frac{\partial(T, S)}{\partial t}=\frac{\partial}{\partial z}\left(K_{H} \frac{\partial(T, S)}{\partial z}\right)
$$

where $K_{H}$ is the vertical eddy diffusivity, $T$ is the water temperature, and $S$ the water salinity. There is no flux of heat or salt through the seabed. At the ice-ocean interface, phase changes during melting or freezing produce heat and freshwater fluxes, which will be considered later in this section.

The effects of turbulence in transferring momentum and mixing heat and salt are determined by the widely used, level 2.5 turbulence closure scheme of Mellor and Yamada (1982) incorporating the modifications of Galperin et al. (1988). This provides vertical viscosity and diffusivity coefficients that depend on the interaction of flow and stratification, which are provided by the relation

$$
K_{M}, K_{H}=q l\left(S_{M}, S_{H}\right),
$$

where $q^{2} / 2$ is the turbulent kinetic energy (TKE), $l$ is turbulence mixing length scale, and $S_{M}$ and $S_{H}$ are stability functions related to the Richardson number. The local evolution of both $q$ and $l$ are given by

$$
\begin{aligned}
\frac{\partial q^{2}}{\partial t}= & \frac{\partial}{\partial z}\left(K_{q} \frac{\partial q^{2}}{\partial z}\right)+K_{M}\left[\left(\frac{\partial u}{\partial z}\right)^{2}+\left(\frac{\partial v}{\partial z}\right)^{2}\right] \\
& +\frac{2 g}{\rho_{0}} K_{H} \frac{\partial \rho}{\partial z}-\frac{2 q^{3}}{B_{1} l} \\
\frac{\partial q^{2} l}{\partial t}= & \frac{\partial}{\partial z}\left(K_{q} \frac{\partial q^{2} l}{\partial z}\right)+l E_{1} K_{M}\left[\left(\frac{\partial u}{\partial z}\right)^{2}+\left(\frac{\partial v}{\partial z}\right)^{2}\right] \\
& +\frac{l E_{1} g}{\rho_{0}} K_{H} \frac{\partial \rho}{\partial z}-l w \frac{q^{3}}{B_{1} l} .
\end{aligned}
$$

The terms on the right-hand side are, respectively, the vertical turbulent diffusion, shear production, buoyancy production, and dissipation of turbulent kinetic energy; $B_{1}$ and $E_{1}$ are empirical constants, $\rho_{0}$ is the seawater reference density, and $K_{q}$ is the vertical turbulent diffusivity for $q^{2}$ and $q^{2}$ l. A wall proximity function $(w)$ is used to maintain a log-law near the boundaries. The seawater density $(\rho)$ is related to temperature and salinity by the equation of state (Gill 1982).

At the ice-ocean interface melting is a function of temperature, salinity, and speed of the water adjacent to the interface. As the interface is approached eddies are suppressed and the eddy diffusivity decreases to a point where molecular diffusion becomes the principal transfer mechanism for heat and salt. The parameterization of transfer coefficients for heat $\left(\gamma_{t}\right)$ and salt $\left(\gamma_{s}\right)$ follow Kader and Yaglom (1972)

$$
\begin{aligned}
\gamma_{t} & =\frac{u_{*}}{2.12 \ln \left(u_{*} D / \nu\right)+12.5 \operatorname{Pr}^{2 / 3}-9} \\
\gamma_{s} & =\frac{u_{*}}{2.12 \ln \left(u_{*} D / \nu\right)+12.5 \mathrm{Sc}^{2 / 3}-9},
\end{aligned}
$$

where Pr and Sc are the molecular Prandtl and Schmidt numbers for seawater, $\nu$ is the kinematic viscosity, $u_{*}$ 
is the friction velocity, and $D$ is the layer thickness adjacent to the ice shelf.

Basal melt rate, $m$ (negative for melting) is determined from Nicholls et al. (2001)

$$
m=\left[\gamma_{t}\left(T_{b}-T_{f}\right)\right] /\left[a S_{b} \frac{\gamma_{t}}{\gamma_{s}}-\frac{L}{c_{w}}-\left(T_{i}-T_{f}\right) \frac{c_{i}}{c_{w}}\right],
$$

where $T_{b}$ and $S_{b}$ are the temperature and salinity of the seawater adjacent to the ice-ocean interface; $c_{w}$ and $c_{i}$ are the specific heat capacities of seawater and ice; $L$ and $T_{i}$ are the latent heat of ice fusion and ice shelf surface temperature; $T_{f}$ is the pressure freezing point for seawater of salinity $S_{f}$ at the ice-ocean interface and is determined from the linear form of pressure freezing point relationship (Millero 1978)

$$
T_{f}=a S_{f}+b+c p_{i o},
$$

where $a, b$, and $c$ are physical constants $\left(-0.0573^{\circ} \mathrm{C}\right.$ $\mathrm{psu}^{-1}, 0.0832^{\circ} \mathrm{C}$, and $\left.7.61 \times 10^{-4{ }^{\circ}} \mathrm{C} \mathrm{dbar}^{-1}\right)$, and $p_{i o}$ is the pressure at the ice-ocean interface in dbar.

During the production of melt water, heat is required to warm the ice to the in situ melting point and melt the ice prior to mixing. Assuming the salinity of the ice is zero, the bulk change in temperature $(\Delta T)$ and salinity $(\Delta S)$ for the 1-m thick layer adjacent to the ice shelf base over the time step $(\Delta t)$ is prescribed by

$$
\Delta T=\frac{\Delta M}{M_{b}+\Delta M}\left\{\left[T_{f}-\frac{L}{c_{w}}-\frac{c_{i}}{c_{w}}\left(T_{f}-T_{i}\right)\right]-T_{b}\right\}
$$

and

$$
\Delta S=-\frac{\Delta M}{M_{b}+\Delta M} S_{b},
$$

where $\Delta M$ is the meltwater mass determined from (16) and $M_{b}$ is the layer water mass.

To examine the vertical structure of the $M_{2}$ tidal currents, the resulting $u$ and $v$ model velocity data from (5) and (6) are analyzed to determine the amplitude $\left(A_{u}\right.$, $\left.A_{v}\right)$ and phase $\left(\phi_{u}, \phi_{v}\right)$ of the velocity components. These data are used to construct clockwise and anticlockwise rotary components (Souza and Simpson 1996):

$$
\begin{aligned}
& R_{+}=\left|0.5\left[A_{u}^{2}+A_{v}^{2}+2 u v \sin \left(\phi_{v}-\phi_{u}\right)\right]^{1 / 2}\right| \\
& R_{-}=\left|0.5\left[A_{u}^{2}+A_{v}^{2}-2 u v \sin \left(\phi_{v}-\phi_{u}\right)\right]^{1 / 2}\right| .
\end{aligned}
$$

When viewed from above, $R_{-}$and $R_{+}$are the purely clockwise and anticlockwise constant magnitude velocity vectors that rotate at the tidal frequency. These two components combine to give the time-varying velocity vector that results in the tidal current ellipse (Prandle $1982)$ and are used to determine the semimajor $(U)$ and semiminor $(V)$ axes and polarization, from (1), of the tidal ellipse:

$$
\begin{aligned}
& U=\left|R_{+}\right|+\left|R_{-}\right| \\
& V=\left|R_{+}\right|-\left|R_{-}\right| .
\end{aligned}
$$

In this study, the one-dimensional model simulations are for a 200-m water column beneath an ice shelf with a surface temperature of $-27^{\circ} \mathrm{C}$, similar to the more tidally active regions close to the Ronne Ice Front, around Korff and Henry Ice Rises, and close to grounding lines. The surface forcing is ramped up over approximately 16 tidal cycles and the model allowed to stabilize. The wintertime conditions found on Berkner Shelf are used to provide the initial water column temperature and salinity of $-1.9^{\circ} \mathrm{C}$ and $34.65 \mathrm{psu}$ and the ice shelf draft of $250 \mathrm{~m}$ is similar to that found along the Ronne Ice Front. Although these initial oceanographic conditions and ice shelf draft represent a particular region, the temperature and salinity range is relatively small beneath FRIS (approximately $-1.90^{\circ}$ to $-2.55^{\circ} \mathrm{C}$ and 34.77 to $34.48 \mathrm{psu}$ ) (Nicholls et al. 2001; Nicholls and Makinson 1998) and the model results will provide an insight into the broad pattern of tidal mixing regimes within the sub-ice-shelf cavity.

\section{Model result}

\section{a. Tidal current profiles in a homogeneous sea}

To maintain the initial homogeneous water column conditions throughout this simulation the model is thermodynamically decoupled from the ice shelf to prevent melting and subsequent stratification of the water column. However, the ice shelf base remains a second frictional surface, doubling the amount of water column occupied by boundary layers. In some regions the high water velocity or proximity to the critical latitude, or a combination of the two, will lead to the combined boundary layer thickness exceeding that of the water column. Therefore as the two boundary layers interact, the amplitude of $R_{+}$throughout the water column is below its "free stream" velocity. Keeping the $M_{2}$ surface forcing parameters constant (e.g., $U=0.3 \mathrm{~m} \mathrm{~s}^{-1}$ and $P=0.0$ ) and allowing the model to stabilize, the resulting tidal currents are analyzed to obtain the rotary current profiles. Figure 3 illustrates the retarding effect of the two interacting boundary layers on $R_{+}$as the $M_{2}$ critical latitude is approached from the south.

Observations from the southern Weddell Sea (Foldvik et al. 1990; Foldvik et al. 2001) support the prediction that for semidiurnal tides the amplitude of $R_{-}$is largely depth independent while the amplitude of $R_{+}$is strongly depth dependent. The net water column velocity structure results from the addition of the two components and their associated boundary layers, and so the tidal current ellipse polarization is depth dependent, becoming increasingly negative toward the boundaries (Fig. 3).

To examine the latitudinal extent of the combined effects of critical latitude and velocity on water column structure, a range of surface forcing values for $U$ are applied at different latitudes while maintaining $P=0.0$. The resulting $M_{2}$ amplitude of $R_{+}$at the midpoint in the 


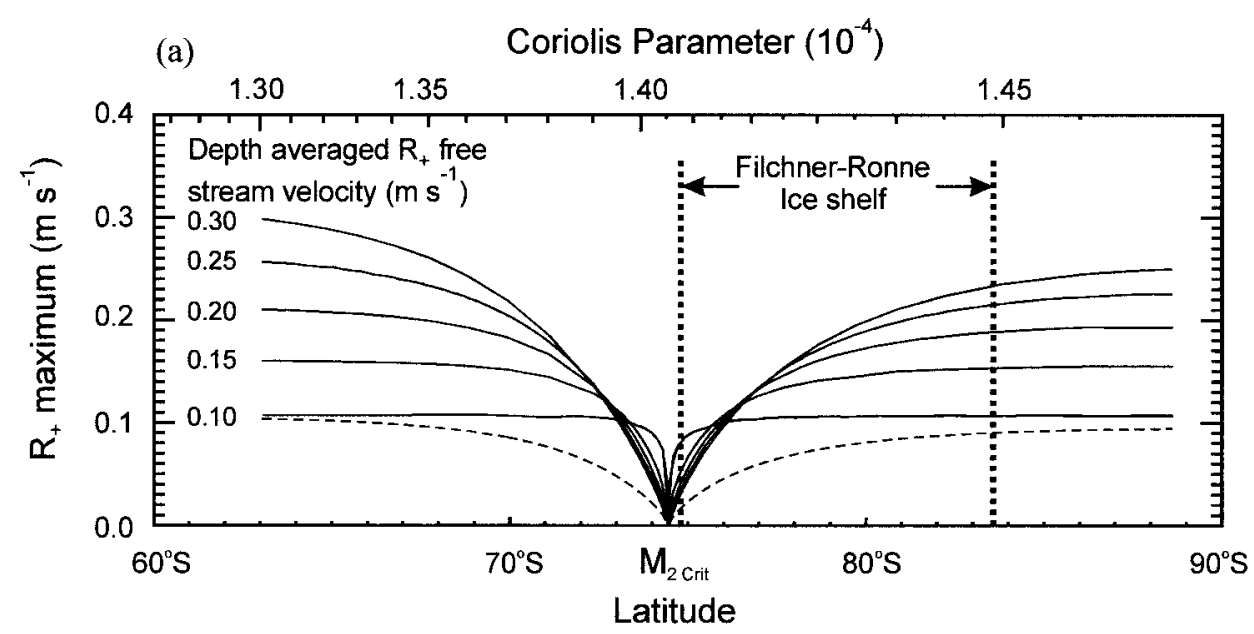

(b)

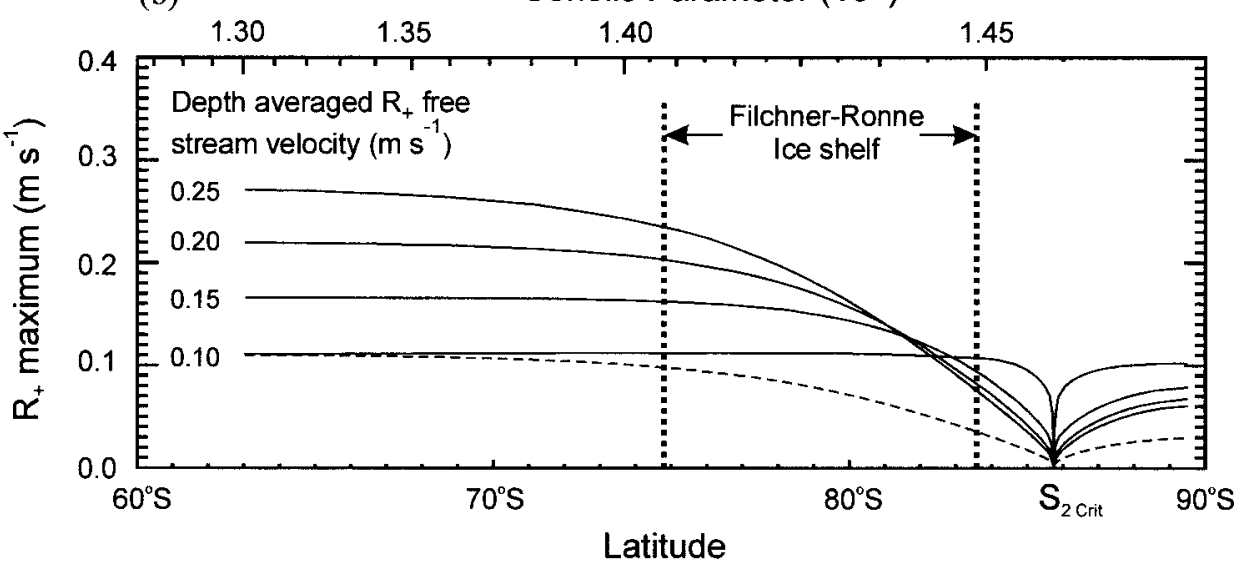

FIG. 4. The amplitude of (a) the $M_{2}$ and (b) the $S_{2}$ anticlockwise component $\left(R_{+}\right)$at the mid-water column along a transect spanning the critical latitude. Several free stream amplitudes were used to illustrate the combined effect of critical latitude and water velocity in the 200-m homogeneous water column. The dashed line represents $R_{+}$in a $100-\mathrm{m}$ water column. The region where the two boundary layers interact and retard the flow is greatest at highest velocities or in shallower water. The position of FRIS lies between the dotted lines and the asymmetry in the plots results from the nonlinear variation of the Coriolis parameter with latitude.

water column is shown in Fig. 4a. Here, the greatest impact is at the critical latitude where all $R_{+}$amplitudes are affected. The range of influence is dependent on the water velocity, with higher velocities affected the most because of their larger boundary layers. It follows that shallower water would also extend the latitudinal range of influence. By reducing the water column thickness to $100 \mathrm{~m}$ and maintaining the same forcing, the dashed line in Fig. 4a shows the greater latitudinal range over which the two boundary layers occupy the entire water column and retard the flow. Conversely, in deeper water the latitudinal range will decrease. While the northern part of FRIS lies close to the $M_{2}$ critical latitude, the southernmost areas of the ice shelf are closest to the $S_{2}$ critical latitude. The amplitude pattern of the $S_{2}$ tidal currents mirror those of $M_{2}$ beneath FRIS, though they are approximately $40 \%$ smaller (Makinson and Nicholls
1999). Applying the model in the same way, the resulting $S_{2}$ amplitude of $R_{+}$at the midpoint in the water column is shown in Fig. $4 \mathrm{~b}$ to illustrate the range of influence of the $S_{2}$ boundary layers. The remainder of the modeling will now focus on $M_{2}$ tidal currents only; however, the characteristics of $M_{2}$ tidal currents will also be representative of the $S_{2}$ tidal currents.

\section{b. Tidal current profiles in a stratified sea}

To simulate the effects of stratification the model is thermodynamically coupled to the ice shelf allowing melting to take place. The model is initially allowed to stabilize over $80 M_{2}$ tidal cycles using an unstratified water column and constant surface-forcing parameters ( $U=0.3 \mathrm{~m} \mathrm{~s}^{-1}$ and $P=0.0$ ). Over a further 200 cycles (about 103 days) melting is enabled and a pycnocline 


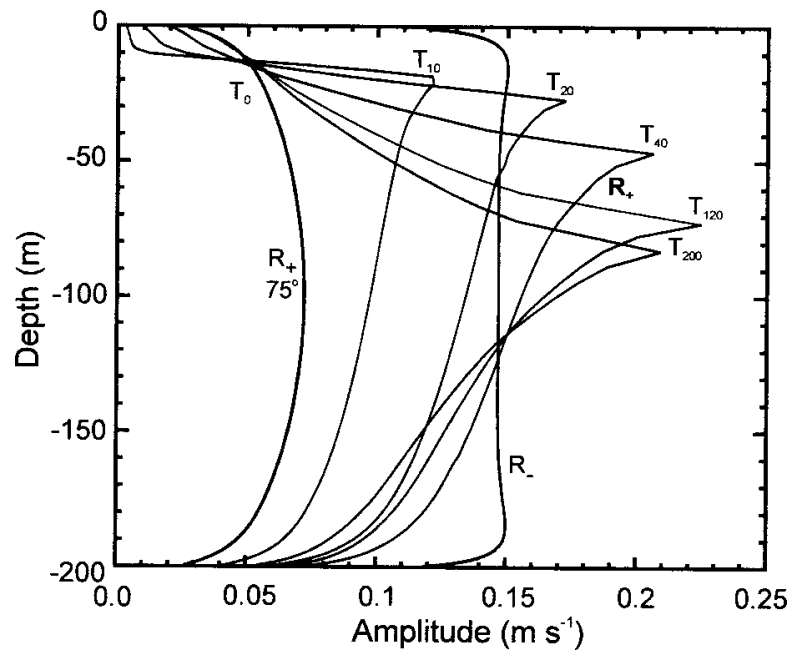

FIG. 5. The vertical structure of the $M_{2}$ rotary components beneath an ice shelf during the onset of melting and development of a deepening pycnocline. In this example, $T_{0}$ represents $R_{+}$at $75^{\circ} \mathrm{S}$ before melting is initiated and $T_{10}$ through to $T_{200}$ indicate the number of tidal cycles over which melting has taken place. Initially the flow is retarded, but attains its free stream velocity in the part of the water column association with the pycnocline. After 200 tidal cycles there is no significant change in $R_{+}$or the depth of the pycnocline.

is quickly established in the upper half of the water column. To represent a well-mixed inflowing water mass, the deepest $20 \mathrm{~m}$ of the water column are held at their initial temperature and salinity conditions throughout the model run. However, vertical mixing creates a lower mixed layer that extends through most of the lower $100 \mathrm{~m}$. As the water column structure is modified by melting and mixing the development of the tidal current structure beneath the ice shelf is shown in Fig. 5. Here the reference latitude is $75^{\circ} \mathrm{S}$ but other latitudes close to the critical latitude would give a similar pattern of results. Initially the two $R_{+}$boundary layers occupy the entire water column and the flow associated with the $R_{+}$component is retarded below its free stream velocity. As melting progresses, the water column stratifies and the maximum $R_{+}$velocity tracks the deepening pycnocline. In this example, $R_{+}$shows a two- to threefold increase over the nonstratified case as it attains its free stream velocity in the vicinity of the pycnocline, though farther away from the critical latitude this increase would be smaller. The final $M_{2}$ tidal current structure in Fig. 5 is almost identical to the observations beneath fast-ice in the Canadian Arctic, confirming that the $M_{2}$ tidal current close to the critical latitude reaches a maximum at the depth of the pycnocline (Prinsenberg and Bennett 1989).

The effect of the stratification on $R_{+}$depends both on the strength of the building pycnocline and on the initial level of retardation compared with the free stream velocity. This increases for increasing free stream velocities and as the critical latitude is approached (Fig. 4). In areas subject to changes in strat- ification, either on daily, spring-neap or seasonal time scales, the $R_{+}$component can exhibit substantial fluctuations in amplitude. Similar conditions arise in the North Sea where the bottom boundary layer outcrops at the surface: observations show significant differences in the vertical tidal current structure between the well-mixed winter conditions, where the flow remains retarded, and stratified summer conditions where the flow attains its free stream value above the pycnocline (Howarth 1998). Simpson and Souza (1995) found similar changes in tidal current structure on a semidiurnal timescale near the Dutch coast in the freshwater region of the Rhine outflow.

\section{c. Polarization effects}

The one-dimensional vertical mixing model has been used to simulate a wide range of different current amplitudes and ellipse polarizations for the $M_{2}$ tidal constituent at $79^{\circ} \mathrm{S}$, the mean position of FRIS. Once the model has stabilized after 80 tidal cycles using an unstratified water column, melting is initiated. The surface forcing parameters remain unchanged while the stratification evolves over a further 120 cycles (about 62 days) with the lowest $20 \mathrm{~m}$ of the water column held at constant temperature and salinity throughout. The melt rates, which are initially high for all polarizations, decrease as the mixed layer next to the ice shelf base cools toward the in situ freezing point. Tidal currents with a more positive polarization however, continue to deepen the mixed layer and pycnocline toward the middle of the water column, maintaining a strong vertical heat flux and higher rates of melting. This dependence of vertical mixing on ellipse polarization was highlighted by Simpson and Sharples (1994) for northern midlatitudes.

To illustrate the extent of mixing meltwater from the ice shelf base down through the upper half of the water column, the dependence of the pycnocline depth after 10 tidal cycles on mean polarization is plotted in Fig. 6 for a range of tidal current strengths. After only 10 tidal cycles the vigorous mixing, associated with strong tidal currents and positive polarizations, has deepened the pycnocline almost to the middle of the water column. While the temperature and salinity remain fixed in the lower part of the water column the pycnocline depth will not exceed $100 \mathrm{~m}$ or half the water column thickness. Clearly there is asymmetry in the resulting thickness of the mixed layers, which is dependent on the ratio and magnitude of the two rotary currents and, therefore, on the magnitude and polarization of the tidal current ellipse. For predominantly clockwise tidal currents $(P<-0.5)$ the depth of the pycnocline is constrained by the depth of the $R_{-}$boundary layer. As the polarization becomes more positive, the boundary layer of $R_{+}$becomes increasingly influential producing more mixing in the midwater column and rapidly deepening the pycnocline over the region $-0.3<P<0.3$. With 


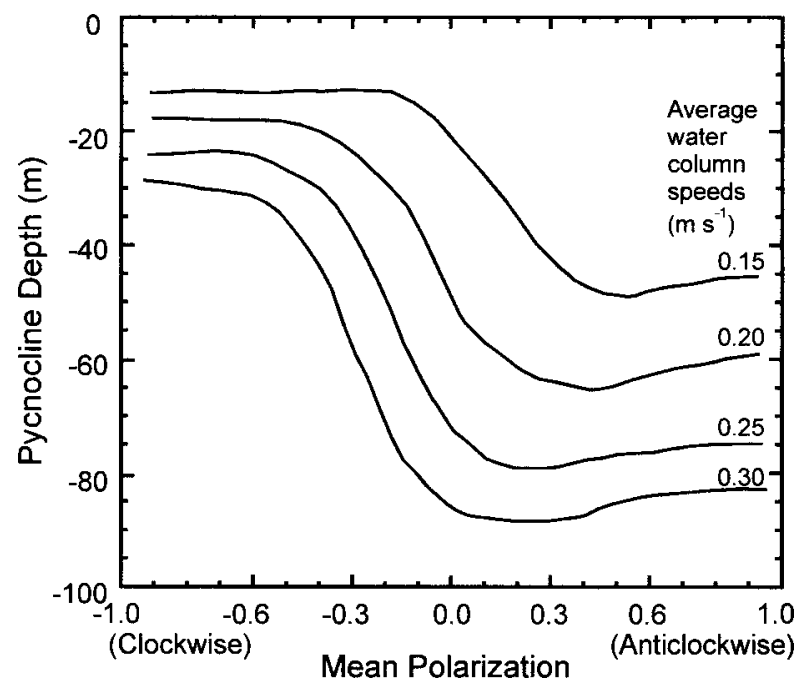

FIG. 6. Pycnocline depth in the upper half of the water column after $10 M_{2}$ tidal cycles at $79^{\circ} \mathrm{S}$ over which melting has taken place for different average water column speeds vs the mean polarization of the $M_{2}$ tidal current ellipse.

no significant increase in midwater column mixing as the polarization increases, there is no further deepening of the pycnocline for the predominantly anticlockwise tidal currents $(P>0.5)$.

Applying a broader range of surface forcings, the dependence after 10 tidal cycles of pycnocline depth on the resulting mean rotary components of the tidal current ellipse is contoured in Fig. 7. Here strong tidal currents and positive polarizations result in the pycnocline depth almost reaching its maximum of $100 \mathrm{~m}$, whereas negative polarizations give a much shallower pycnocline. Given sufficient time, the middle of the pycnocline would lie close to the middle of the water column for all forcings as the water column structure, vertical heat flux, and melt rate reached an equilibrium state. Assuming the water column structure is approaching equilibrium after 120 tidal cycles for all but the weakest tidal currents, the melt rate is contoured in Fig. 8. There is a strong dependence of both the pycnocline depth and the melt rate on polarization of the tidal current ellipse, with both parameters showing a similar pattern. For both parameters, the deepest pycnocline and highest melt rates are associated with the more positive polarizations. The greatest changes in melt rate occur over the range $-1.0<P<0.2$, as the $R_{+}$boundary layers introduce increasing levels of mixing into the mid-water column, bringing warmer water up to the ice shelf base. Beyond this polarization range the longer-term melt rate shows a slight decrease for given average water speeds. This decrease can be attributed to no significant change in the mid-water column mixing combined with a decreasing boundary velocity as the shear from $R_{-}$diminishes with increasing polarization.

\section{Application to FRIS}

The broad range of surface forcings applied to the model generate a wide range of tidal currents that are analyzed to obtain the mean rotary components. Therefore, the effects of latitude on the tidal current structure will be embedded within the mean $R_{+}$and $R_{-}$components. Since FRIS occupies a narrow band of latitudes $\left(79^{\circ} \mathrm{S} \pm 4^{\circ}\right)$ the dependence of pycnocline depth and melt rate on mean $R_{+}$and $R_{-}$should vary little with position on the ice shelf. However, the influence of proximity to the critical latitude on the $R_{+}$component results in some differences from the data at $79^{\circ} \mathrm{S}$ in Figs. 7 and 8 . The greatest differences of up to $20 \%$ occur for positive polarizations and speeds below $0.25 \mathrm{~m} \mathrm{~s}^{-1}$, where the contribution of turbulence from $R_{+}$dominates the vertical mixing. Here, the critical latitude strongly influences the $R_{+}$current component (Fig. 4a) with additional turbulence being generated from the increased shear as $R_{+}$attains its free stream velocity around the developing pycnocline (Fig. 5). This results in higher melt rates and slightly shallower pycnocline depths as the critical latitude is approached. For negative polarizations and higher current speeds there is little or no latitudinal influence. Consequently, the model results from $79^{\circ} \mathrm{S}$ are broadly representative of the range of latitudes occupied by FRIS.

Beneath the ice shelf, the modeled $M_{2}$ and $S_{2}$ tidal velocities can reach $0.5 \mathrm{~m} \mathrm{~s}^{-1}$ and $0.3 \mathrm{~m} \mathrm{~s}^{-1}$, respectively, typically three to six times higher than for the diurnal tides (Makinson and Nicholls 1999). The $M_{2}$ ellipse polarization ranges from -0.95 to +0.7 (Fig. 2) with predominantly anticlockwise rotation associated with the shallow water close to the Ronne Ice Front. In the central part of Ronne Ice Shelf and at the mouths of the ice stream and glacier inlets predominantly clockwise rotation occurs, which results from the interaction of a semidiurnal Kelvin wave with basins or inlets of different scales (Carbajal 1997).

The almost complete range of possible polarizations present beneath FRIS suggests that, in light of the model results, a wide range of vertical mixing regimes will exist. The boxes in Figs. 7 and 8 broadly divide the tidal current characteristics beneath FRIS into three main regions. However, the melt rates in Fig. 8 are not predicting basal melt rates beneath FRIS, only the contribution that tidal vertical mixing makes to the heat supply at the ice shelf base. Taking a representative point from each of these three tidal current regions beneath FRIS (indicated by the crosses in Fig. 7), profiles from the model of mixing length, turbulent kinetic energy, eddy viscosity, dissipation, and density change are plotted in Fig. 9. The model was spun up and allowed to stabilize over 80 tidal cycles. The profiles are plotted at hourly intervals over the final $M_{2}$ tidal cycle prior to melting and then after a further 10 tidal cycles, with melting, to show the effects of stratification.

Regions where $P<-0.3$ in water approximately 200 

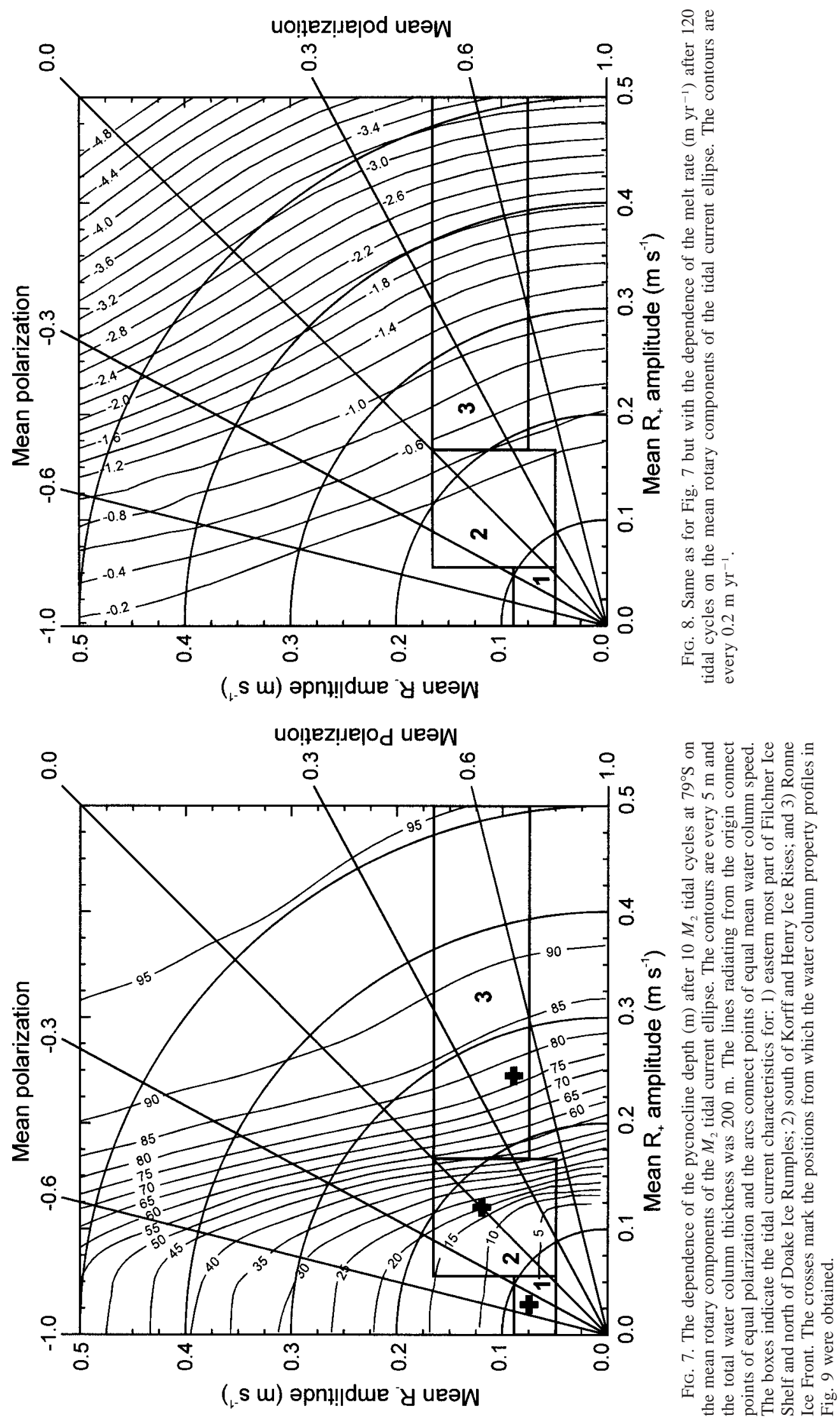
(a)

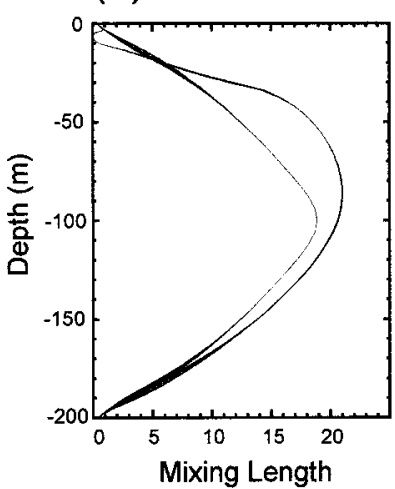

(m)

(b)

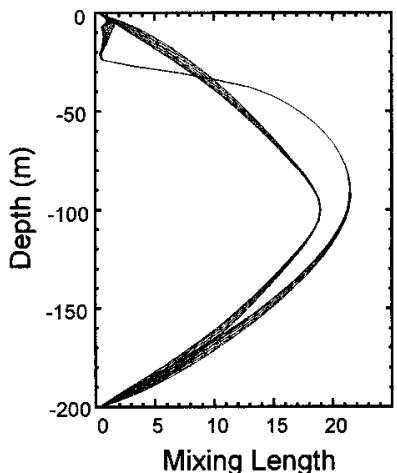

(m)

(c)

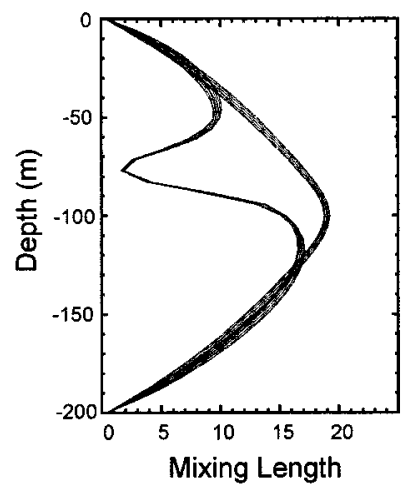

(m)

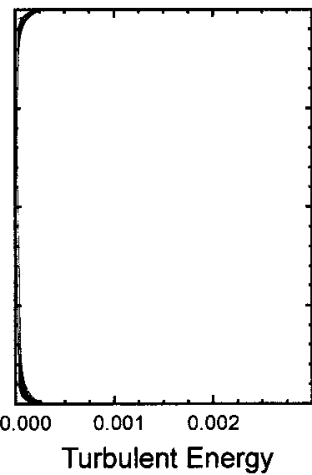

$\left(\mathrm{m}^{2} \mathrm{~s}^{-2}\right)$

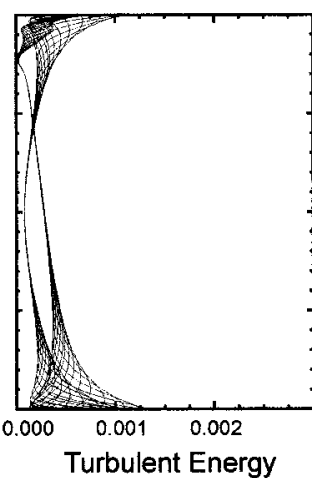

$\left(\mathrm{m}^{2} \mathrm{~s}^{-2}\right)$

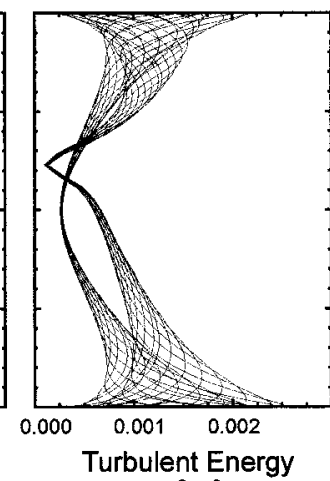

$\left(\mathrm{m}^{2} \mathrm{~s}^{-2}\right)$

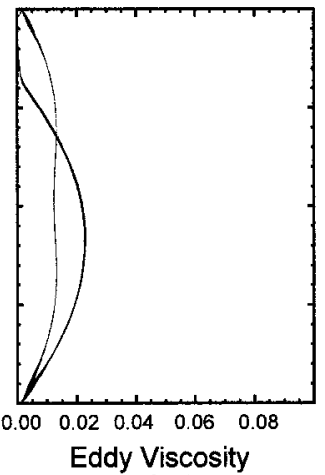

$\left(\mathrm{m}^{2} \mathrm{~s}^{-1}\right)$

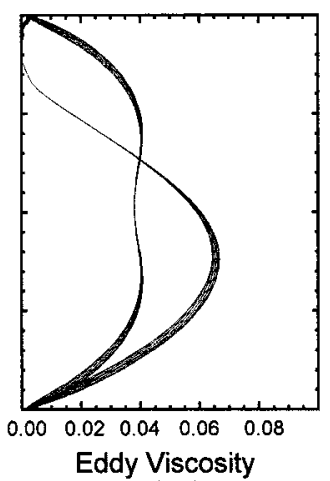

$\left(\mathrm{m}^{2} \mathrm{~s}^{-1}\right)$

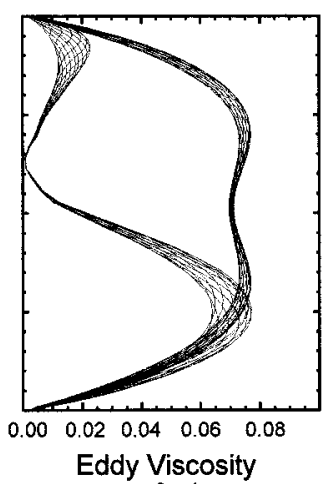

$\left(\mathrm{m}^{2} \mathrm{~s}^{-1}\right)$

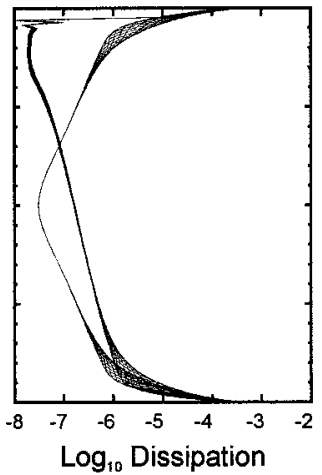

$\left(\mathrm{m}^{2} \mathrm{~s}^{-3}\right)$

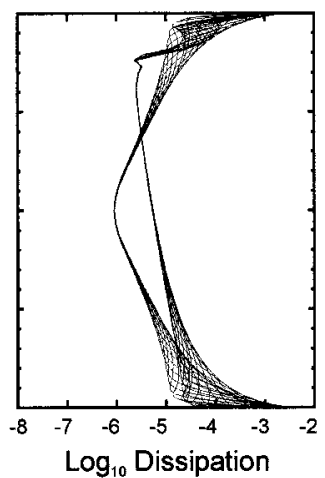

$\left(\mathrm{m}^{2} \mathrm{~s}^{-3}\right)$

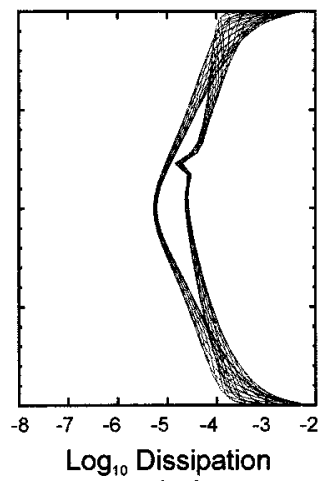

$\left(\mathrm{m}^{2} \mathrm{~s}^{-3}\right)$

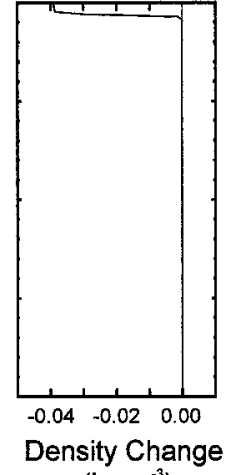

$\left(\mathrm{kg} \mathrm{m}^{-3}\right)$

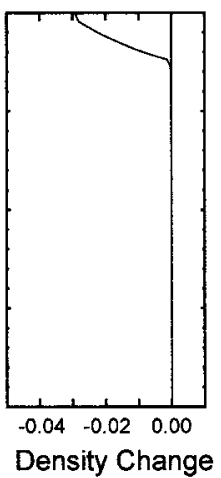

$\left(\mathrm{kg} \mathrm{m}^{-3}\right)$

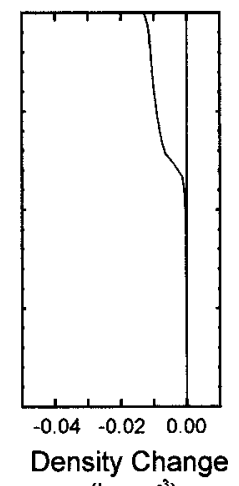

$\left(\mathrm{kg} \mathrm{m}^{-3}\right)$

FIG. 9. Profiles through a 200-m water column of mixing length, turbulent kinetic energy, eddy viscosity, dissipation, and density change. The profiles are at hourly intervals over a $M_{2}$ tidal cycle for a homogeneous water column (symmetrical profiles) and after melting takes place over $10 M_{2}$ tidal cycles (nonsymmetrical profiles). The resultant stratification and pycnocline depth are shown by the change in density from the initial homogeneous conditions. The three locations are indicated by crosses in Fig. 7 and are representative of the three regions beneath FRIS (a) easternmost part of Filchner Ice Shelf and north of Doake Ice Rumples (box 1); (b) south of Korff and Henry Ice Rises (box 2); and (c) Ronne Ice Front (box 3).

$\mathrm{m}$ deep are confined to a few small areas such as the easternmost part of Filchner Ice Shelf and just to north of Doake Ice Rumples. The combination of weak tidal currents and negative polarization (region 1 in Figs. 6 and 7) produce low levels of TKE (Fig. 9a). The turbulent dissipation is greatest close to the boundaries followed by an almost linear decrease on a $\log _{10}$ scale with distance away from the boundaries, characteristic of all the dissipation profiles in Fig. 9. The effect of stratification on the water column is to suppress turbulence, inhibiting the transfer of momentum and reducing the eddy viscosity, particularly in the vicinity of the pycnocline. The pycnocline effectively separates the water column into two parts with TKE generated at the 
upper boundary being confined to a small upper mixed layer. This small mixed layer cools rapidly toward the in situ freezing point, creating a large density contrast across the pycnocline. The remainder of the water column comes under the influence of the lower boundary with the pycnocline acting effectively as a free surface. Consequently, TKE and dissipation increase in the midwater column, increasing both the eddy viscosity and mixing length over a large portion of the lower water column (Fig. 9a).

Other regions where $P<-0.3$ such as the central Ronne Ice Shelf and mouths of ice stream inlets, the water column thickness can be up to $600 \mathrm{~m}$ with low speed tidal currents, compounding the effects of low polarization. Although the model does not specifically cover these water thicknesses, it can be inferred that vertical mixing will be confined to the small boundary layers of $R_{-}$and the upper and lower boundary layers will be isolated from each other. In this situation, turbulence generated from tidal currents will not contribute to mid-water-column mixing, and melt resulting from tidal vertical mixing will be close to zero. However, where heat is available from horizontal advection in the upper mixed layer tidal currents will enhance the basal melting.

Most of FRIS lies between $P= \pm 0.3$, similar to the region south of Korff and Henry ice rises. This region is characterized by moderate tidal currents and a water column around $200 \mathrm{~m}$ thick (Fig. 1). Its $M_{2}$ polarization and velocity range occupies region 2 in Figs. 6 and 7 , with representative water column properties shown in Fig. 9b. When compared with region 1, the moderate tidal currents provide increased TKE, enhancing the eddy viscosity and leading to a deeper penetration of the pycnocline into the water column. Other water column characteristics develop in the same way as in region 1 (Fig. 9a). The initial development and penetration into the water column of the pycnocline is sensitive to changes in polarization over this range $(P= \pm 0.3)$ and the increasing polarization can lead to a three- to fourfold increase in the pycnocline depth (Fig. 6). The longer term melt rate is less sensitive where the polarization is positive, however, once the polarization falls below $P=0$ the melt rate begins to decline rapidly (Fig. 8). In areas where tidal currents are constrained to flow approximately parallel to grounding lines $\left(R_{+} \approx R_{-}\right)$, such as the Orville coast and south of the ice rises, modification of the ellipse polarization is not possible, therefore the transverse pressure gradient must balance the Coriolis force to maintain flow parallel to the coast. Here, there will be regions extending from grounding lines that are dominated by the interacting $R_{+}$boundary layers and therefore exhibit high levels of mixing.

The Ronne Ice Front region is characterized by shallow water $(<200 \mathrm{~m})$, strong tidal currents, positive ellipse polarizations $(0.3<P<0.7)$ and occupies region 3 in Figs. 6 and 7. In this high current regime intense mixing takes place, with rapid deepening of the pyc- nocline and strong melting sustained for as long as the water column remains above the in situ freezing point. These features are shown in Fig. 9c, with high levels of TKE extending into the midwater column, forming a deep pycnocline with the smallest density contrast of the three regions. This small density contrast after 10 tidal cycles is the result of the rapid mixing of meltwater down into the midwater column while maintaining a strong vertical heat flux, keeping the upper water column above the in situ freezing point and maintaining further melting.

\section{Conclusions}

The application of a 1D turbulent closure model, thermodynamically coupled to an ice shelf, has shown the role played by tidal currents under the influence of the earth's rotation in vertical mixing. The model shows that vertical tidal current structure under ice shelves is dramatically modified by the proximity of critical latitudes and changes in stratification; and both the pycnocline development and basal melt rate are sensitive to tidal current ellipse polarization. Beneath FilchnerRonne Ice Shelf, which is bounded by the critical latitudes of the $M_{2}$ and $S_{2}$ semidiurnal tides, several key areas experience the extremes of the polarization range, creating regions of widely differing levels of tidally induced vertical mixing and basal melting. The key results from this study are

1) For predominantly clockwise rotation the model predicts mixing restricted by the small boundary layer of the $R_{-}$rotary component.

2) As the polarization becomes increasingly positive, the thickening boundary layer and associated shear of $R_{+}$causes the mixing to rapidly penetrate deeper into the midwater column.

3) The resultant melting gives over an order of magnitude difference between the lowest melt rates for purely clockwise tidal currents and the highest for purely anticlockwise tidal currents.

4) Changes in stratification can dramatically modify the vertical tidal current structure, particularly near semidiurnal critical latitudes.

As a consequence of these points, simple parameterizations of tidally induced vertical mixing for use in sub-ice-shelf circulation models are unlikely to represent the combined effects of semidiurnal critical latitudes, stratification, and ellipse polarization. Ultimately, a more comprehensive representation of tides and their associated mixing processes will be needed to determine their contribution to sub-ice-shelf circulation.

Acknowledgments. The author wishes to thank Keith Nicholls and two anonymous reviewers for many valuable comments that significantly improved the manuscript. 


\section{APPENDIX}

\section{Surface Forcing Functions}

To derive a surface forcing function in terms of the resulting tidal ellipse polarization and its semimajor axis, the complex form of the momentum equations are required. For details of their derivation the reader is referred to either Soulsby (1983) or Carbajal (2000), where both the velocity and sea surface slope are divided into two counterrotating components

$$
\begin{gathered}
i(\omega+f) R_{+}=\frac{\partial}{\partial z}\left(K_{M} \frac{\partial R_{+}}{\partial z}\right)-g S_{+} \\
-i(\omega-f) R_{-}=\frac{\partial}{\partial z}\left(K_{M} \frac{\partial R_{-}}{\partial z}\right)-g S_{-},
\end{gathered}
$$

where $\omega$ is the tidal frequency, $f$ is the Coriolis parameter, $K_{M}$ is the vertical eddy viscosity, $g$ the gravitational acceleration, and $z$ is vertical distance; $R_{-}$and $R_{+}$represent the purely clockwise and anticlockwise constant magnitude velocity vectors that rotate at the tidal frequency, and $S_{-}$and $S_{+}$are the rotary components of the sea surface elevation gradients. Outside the boundary layer away from the influence of bottom friction, the first terms on the right-hand side of (A1) and (A2) are small and the free stream tidal current is given by

$$
\begin{aligned}
& R_{\infty+}=\frac{i g S_{+}}{\omega+f} \text { and } \\
& R_{\infty-}=\frac{-i g S_{-}}{\omega-f} .
\end{aligned}
$$

Assuming the maximum tidal current corresponds to the maximum surface slope aligned along the $x$ axis $\left(S_{x}\right)$ and the minimum tidal current corresponds to the minimum surface slope aligned along the $y$ axis $\left(S_{y}\right)$

$$
\begin{aligned}
& S_{x}=\left|S_{+}\right|+\left|S_{-}\right| \\
& S_{y}=\left|S_{+}\right|-\left|S_{-}\right|,
\end{aligned}
$$

rearranging (A3) and (A4) and substituting into (A5) and (A6) gives $S_{x}$ and $S_{y}$ in terms $R_{+}$and $R_{-}$. Rearranging and grouping $R_{+}$and $R_{-}$in terms of the maximum tidal current or semimajor axis $\left(U=R_{+}+R_{-}\right)$ and polarization $\left(P=\left[R_{+}-R_{-}\right] /\left[R_{+}+R_{-}\right]\right)$gives

$$
\begin{aligned}
& S_{x}=\frac{U(\omega+P f)}{g} \\
& S_{y}=\frac{U(f+P \omega)}{g}
\end{aligned}
$$

the surface forcing functions along the $x$ and $y$ axes.

\section{REFERENCES}

Carbajal, N., 1997: Two applications of Taylor's problem solution for finite rectangular semi-enclosed basis. Cont. Shelf Res., 17, 803817.
_ 2000: A criterion to locate regions with anticyclonic tidal current rotation. Cont. Shelf Res., 20, 281-292.

Foldvik, A., and T. Gammelsrød, 1988: Notes on Southern Ocean hydrography, sea-ice and bottom water formation. Palaeogeogr. Palaeoclimatol. Palaeoecol., 67, 3-17.

- J. H. Middleton, and T. D. Foster, 1990: The tides of the southern Weddell Sea. Deep-Sea Res., 37, 1345-1362.

- T. Gammelsrød, E. Nygaard, and S. Østerhus, 2001: Current meter measurements near Ronne Ice Shelf, Weddell Sea: Implications for circulation and melting underneath the FilchnerRonne Ice Shelves. J. Geophys. Res., 106, 4463-4477.

Fox, A. J., and A. P. R. Cooper, 1994: Measured properties of the Antarctic ice sheet derived from SCAR Antarctic digital database. Polar Rec., 30, 201-206.

Furevik, T., and A. Foldvik, 1996: Stability at $M_{2}$ critical latitude in the Barents Sea. J. Geophys. Res., 101, 8823-8837.

Galperin, B., L. H. Kantha, S. Hassid, and A. Rosati, 1988: A quasiequilibrium turbulent energy-model for geophysical flows. J. Atmos. Sci., 45, 55-62.

Ganachaud, A., and C. Wunsch, 2000: Improved estimates of global ocean circulation, heat transport and mixing from hydrographic data. Nature, 408, 453-456.

Gill, A. E., 1982: Atmosphere-Ocean Dynamics. International Geophysical Research Series, Vol. 30, Academic Press, 662 pp.

Howarth, M. J., 1998: The effect of stratification on tidal current profiles. Cont. Shelf Res., 18, 1235-1254.

Kader, B. A., and A. M. Yaglom, 1972: Heat and mass transfer laws for fully turbulent wall flows. Int. J. Heat Mass Transfer, 15, $2329-2351$

Kraus, E. B., and J. S. Turner, 1967: A one-dimensional model of the seasonal thermocline II. The general theory and its consequences. Tellus, 19, 98-105.

Lynch, D. R., J. T. C. Ip, C. E. Naimie, and F. E. Werner, 1996: Comprehensive coastal circulation model with application to the Gulf of Maine. Cont. Shelf Res., 16, 875-906.

MacAyeal, D. R., 1984: Thermohaline circulation below the Ross Ice Shelf: A consequence of tidally induced vertical mixing and basal melting. J. Geophys. Res., 89, 597-606.

Makinson, K., and K. W. Nicholls, 1999: Modeling tidal currents beneath Filchner-Ronne Ice Shelf and on the adjacent continental shelf: Their effect on mixing and transport. J. Geophys. Res., 104, 13 449-13 465.

Mellor, G., and T. Yamada, 1982: Development of a turbulence closure-model for geophysical fluid problems. Rev. Geophys., 20, $851-875$.

Millero, F. J., 1978: Annex 6: Freezing point of seawater. Eighth report of the Joint Panel of Oceanographic Tables and Standards. UNESCO Tech. Pap. Mar. Sci., 28, 29-31.

Nicholls, K. W., and K. Makinson, 1998: Ocean circulation beneath the western Ronne Ice Shelf, as derived from in situ measurements of water currents and properties. Ocean, Ice, and Atmosphere: Interactions at the Antarctic Continental Margin. S. S. Jacobs and R. F. Weiss, Eds., Antarctic Research Series, Vol. 75, Amer. Geophys. Union, 301-318.

—_, S. Østerhus, K. Makinson, and M. R. Johnson, 2001: Oceanographic conditions south of Berkner Island, beneath FilchnerRonne Ice Shelf. Antarctica. J. Geophys. Res., 106, $11481-$ 11492.

Nøst, E., 1994: Calculating tidal current profiles from vertically integrated models near the critical latitude in the Barents Sea. $J$. Geophys. Res., 99, 7885-7901.

Prandle, D., 1982: The vertical structure of tidal currents and other oscillatory flows. Geophys. Astrophys. Fluid Dyn., 22, 29-49.

Prinsenberg, S. J., and E. B. Bennett, 1989: Vertical variations of tidal currents in shallow land fast ice-covered regions. J. Phys. Oceanogr., 19, 1268-1278.

Robertson, R., L. Padman, and G. D. Egbert, 1998: Tidal currents in the Weddell Sea. Ocean, Ice, and Atmosphere: Interactions at the Antarctic Continental Margin. S. S. Jacobs and R. F. Weiss, Eds., Antarctic Research Series, Vol. 75, Amer. Geophys. Union, 341-369. 
Scheduikat, M., and D. J. Olbers, 1990: A one-dimensional mixed layer model beneath the Ross Ice Shelf with tidally induced vertical mixing. Antarct. Sci., 2, 29-42.

Shirasawa, K., and R. G. Ingram, 1991: Characteristics of the turbulent oceanic boundary layer under sea ice. Part 1: A review of the ice-ocean boundary layer. J. Mar. Syst., 2, 153-160.

Simpson, J. H., and J. Sharples, 1994: Does the Earth's rotation influence the location of shelf sea fronts. J. Geophys. Res., 99, 3315-3319.
, and A. J. Souza, 1995: Semidiurnal switching in the region of freshwater influence of the Rhine. J. Geophys. Res., 100, 70377044 .

Soulsby, R. L., 1983: The bottom boundary layer of the shelf sea Physical Oceanography of Coastal and Shelf Seas, B. Johns, Ed., Elsevier, 189-226.

Souza, A. J., and J. H. Simpson, 1996: The modification of tidal ellipses by stratification in the Rhine ROFI. Cont. Shelf Res., 16, 397-414 